\title{
Death Anxiety: An Analysis of an Evolving Concept
}

\author{
Rebecca Helen Lehto, PhD, RN, OCN \\ Michigan State University, East Lansing \\ Karen Farchaus Stein, PhD, RN, FAAN
}

University of Michigan, Ann Arbor

\begin{abstract}
This article identifies defining attributes, antecedents, and consequences of the concept of death anxiety using Rodgers (2000) evolutionary method of concept analysis. The literature on death anxiety was systematically reviewed for the years 1980-2007. Articles were summarized and coded. Inductive data analyses resulted in defining attributes (emotion, cognitive, experiential, developmental, sociocultural shaping, and source of motivation), antecedents (stressful environments and the experience of unpredictable circumstances, diagnosis of a life-threatening illness or the experience of a life-threatening event, and experiences with death and dying), and consequences (adaptive and maladaptive presentations). Results are important because little systematic inquiry of death anxiety exists in nursing literature.
\end{abstract}

Keywords: death anxiety; death; nursing; concept analysis

Death—unto itself-Exception-Is exempt from Change

—Emily Dickinson

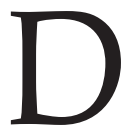
eath is a powerful human concern that has been conceptualized as a powerful motivating force behind much creative expression and philosophic inquiry throughout the ages. Leo Tolstoy, renowned 19th-century Russian moral thinker and novelist, aptly illustrated the human challenges in confronting the inevitability of death and the anxiety it provokes as he vividly describes the last three days of Ivan Ilych's egocentric, seemingly meaningless existence in "The Death of Ivan Ilych." Included in this tale is a depiction of death as a metaphorical private black sack that the anguished Ivan Ilych struggled against but was driven toward by an imperceptible, resistless power (Tolstoy, 1960).

"Death anxiety" is a term used to conceptualize the apprehension generated by death awareness (Abdel-Khalek, 2005). Humans are unique in that they must learn to live and adapt to the consciousness of their own finiteness (Becker, 1973). Thus, a major task for cultural systems is to provide a symbolic structure that addresses 
death and provides meaning for its occurrence and a context for its transcendence (Becker 1973; Kübler-Ross, 2002). Confronting death and the anxiety generated by knowledge of its inevitability is a universal psychological quandary for humans. For health care providers, death is an ever-present reality despite increasing technologically advanced health systems, longer patient survival, and cure from life-threatening conditions. Although helping individuals and their families manage death is a central responsibility of nursing worldwide and an increasing literature suggests that death anxiety contributes to important emotional and behavioral outcomes, theoretical and empirical background of the concept has not been systematically examined in the nursing literature. This limitation has led to a dearth of literature that has explored death anxiety as an important variable in empirical nursing inquiry, a finding that may compromise the development of interventions to assist nursing personnel and the myriad of patients affected in their ability to cope with this profound existential issue. To date, few efforts have been directed toward clarification of this critical concept in nursing (Nyatanga \& de Vocht, 2006), although death anxiety is included as a nursing diagnosis with NANDA nursing outcome criteria (Carpenito-Moyet, 2008; Moorhead, Johnson, Maas, \& Swanson, 2008).

Nyantanga and de Vocht (2006) argue that a clear and comprehensive theoretical definition of the death anxiety concept that integrates the divergent theoretical approaches is not found in the nursing literature despite its critical relevance to palliative care practice and research. Yet death anxiety is an important concept to consider in a wide range of practice settings, including community cancer screenings of healthy individuals, psychiatric care, acute and trauma care, chronic care, and pediatrics and in individuals facing diagnosis of a life-threatening illness. The goal of this article is to help move nursing science forward by identifying important defining attributes, antecedents, and consequences of the concept and to provide a synopsis of this work for nursing utilization and practice.

\section{METHOD}

Using the evolutionary method of concept analyses developed by Rodgers (2000), an extensive online literature search was conducted for this study. Rodgers's (2000) inductive method is characterized by understanding concepts as dynamic, fuzzy, and context dependent rather than as universal and crystal clear. This method of concept analysis involves identifying the concept of interest and related terms, selecting a relevant setting and sample for the data collection, collecting data related to concept attributes and contextual base, analyzing the data and identifying the concept exemplar, and finally developing implications and hypotheses for further concept development. While there are varied methods for conducting concept analyses (Walker \& Avant, 1995), Rodgers approach is well suited for the concept of death anxiety because it is context dependent and changing and may be interpretable only given multiple elements in a certain context. While the goal is to develop and clarify clear concepts that are useful, also inherent is the sense that definition of the concept may vary over time to maintain its usefulness, applicability, and effectiveness (Rodgers, 2000). 
Journal articles were the main source of information for this concept analysis. In addition, eight foundational books were examined (Becker, 1973; Kelly, 1955; Kübler-Ross, 2002; Lonetto \& Templer, 1986; Momeyer, 1988; Neimeyer, 1994; Panksepp, 1998; Yalom, 1980). To narrow findings for this concept analyses to health-related relevance, the search was limited to the health sciences. Inclusion criteria for the concept analysis were articles written in English, health related or nursing relevant, and published since 1980. Commentary papers and papers that were not translated into English were excluded.

The key word "death anxiety" was used, and literature was systematically reviewed from CINAHL, EBM Review, Health and Wellness Resource Center, UM-Medsearch, psychINFO, and PubMed for the years 1980-2007 in August 2007. The search culminated in 135 citations that were retrieved for this analysis. Out of the 135 citations, 17 were eliminated as duplicate citations. From the remaining 118 abstracts, 89 articles that met the inclusion criteria were retrieved and reviewed.

The articles were summarized and coded by each author independently. The effort by two nurse scientists permitted the assurance of interreliability of the coding and summarization of respective articles. An inductive data analysis of the concept of death anxiety was conducted, and themes were identified. The data units included words and sentences that related to or provided answers to the following questions: What are the specific attributes of death anxiety? How is death anxiety defined? How is death anxiety manifested? What factors are associated with death anxiety's presence? How is death anxiety measured? What are the consequences of death anxiety? The articles were grouped according to the characteristics of the concept analyses that they addressed. For example, articles that dealt with measurement issues of the death anxiety concept were placed together and were summarized as a data collective.

\section{FINDINGS}

\section{Attributes of Death AnXIETy}

Six attributes of death anxiety were identified: emotion, cognitive, experiential, developmental, sociocultural shaping, and source of motivation.

Emotion. Death anxiety is closely related to core fear related to the annihilation of one's existence (Greenberg, Pyszczynski, Solomon, Simon, \& Breus, 1994) and stems from fundamental limbic structures that are ancient, hardwired, and adaptive to survival (Panksepp, 1998). The foundational brain systems underlying death anxiety include the amygdala and related structures involved in the development of implicit (nonconscious) fear memories and the hippocampus and related cortical areas involved in the development of explicit (conscious) fear memories. In humans, the two emotional memory systems act in parallel and are activated by the same stimuli simultaneously (in this case threat of death) (LeDoux, 2008). Thus, perceptions of threat associated with death fuse with cognitive processes in the formation of memory structures in humans (e.g., Panksepp, 1998). Emotional memory structures, both implicit and explicit, play important roles in the signaling and regulation of perceived threat (LeDoux, 1996, 2008; Öhman, 2000). It is only 
through careful animal studies that emotional memory systems can be disengaged from each other (LeDoux, 2008). Death anxiety necessarily entails either or both implicit and explicit fear elements to a varying degree that differentially contribute to the actual experience.

Death anxiety is likely a universal human phenomenon given the biological architecture of emotional memory concomitant with higher-level cognitive structures that permit futuristic anticipation and prediction (Becker, 1973; Lonetto \& Templer, 1986; Neimeyer, 1994; Panksepp, 1998; Yalom, 1980). Because of its grounding in negative emotionality, imagery such as corpse viewing can heighten death anxiety (Lonetto, 1982; Lonetto, Mercer, Fleming, Bunting, \& Clare, 1980; McDonald \& Hilgendorf, 1986).

Cognitive. In foundational work, Kelly (1955) identified that death was incompatible with living and thus was incompatible with core cognitive structures. Individuals develop enduring cognitive structures as a result of life experiences, and as much as these structures are living focused, they will be threatened by the concept of death. If death is integrated or becomes a part of core cognitive structures, it is perceived as less of a threat (Kelly, 1955). Cognitive structures, which underlie individualized differences in needs for order and structure, tolerance for ambiguity, and managing uncertainty, impact perceptions of threat and degree of death anxiety (Jost et al., 2007).

Important cognitive components of death anxiety include attitudes, conceptual ability to predict and anticipate the future, and awareness of the salience of death. The cognitions include beliefs about death, images and beliefs regarding the death experience, and the self as dead or no longer existing. In recent work, death anxiety is viewed as a multidimensional cognitive construct (Benton, Christopher, \& Walter, 2007; Cicirelli, 2006) that stems from attitudes toward death that exist as part of cognitive structure (Neimeyer, Wittkowski, \& Moser, 2004). Cognitive dimensions of death anxiety may include beliefs or ideas of the dying process, thoughts of the state of being dead or being destroyed, images of significant others, thoughts about the unknown and the conscious thinking about death, ideas about the body after death, and thoughts of premature death among different individuals (DePaola, Griffin, Young, \& Neimeyer, 2003; Neimeyer, 1994).

Death attitudes, which develop as a result of cumulative life experiences, may better predict the multidimensional nature of death anxiety than factors such as demographic criteria (Neimeyer et al., 2004). Researchers have recognized the importance of beliefs, or cognitive factors, in the perception of threat associated with death. For example, university students taking a thanatology course who were more religious reported less death anxiety, suggesting that religious beliefs buffered and provided a context of meaning for death (Knight \& Elfenbein, 1993). Similarly, certainty in belief in a continued and positive existence after death was associated with lowered death anxiety in a sample of terminally ill patients (Smith, Nehemkis, \& Charter, 1983-1984). Among the elderly, the belief in an afterlife of reward or punishment predicted the relationship between death anxiety and religiosity (Fortner \& Neimeyer, 1999). While studies reveal that committed religious beliefs and practices reduce death anxiety (Alvarado, Templer, 
Bresler, \& Thomas-Dobson, 1995; Glas, 2007; Kraft, Litwin, \& Barber, 1987; Pierce, 2007), the relationship is complex (Neimeyer et al., 2004). Relationships between religiosity and death concerns vary depending on age, gender, and devoutness (Neimeyer et al., 2004; Pierce, 2007). Further, cultural religious orientations influence personal life and death paradigms and thus the experience of death anxiety (Morrow, 2007; Zeyrek, 2006).

Death anxiety is provoked by "the anticipation of a state in which the self does not exist" (Tomer \& Eliason, 1996, p. 345) connoting the importance of conceptual ability to predict and anticipate the future. In turn, this ability increases perceptions of death salience (Tomer \& Eliason, 1996). Death salience (a reminder of personal death/mortality) influences death anxiety by activating perceptions of regret and thoughts relative to the meaning of death, by modifying beliefs about the self, and by activating self-regulatory responses that may include life review, cultural identification, and self-transcendence (Tomer \& Eliason, 1996).

Experiential. Death anxiety is largely denied or repressed, and this is adaptive because it reduces the possibility of paralyzing fear and terror that would impede survival (e.g., Becker, 1973; Yalom, 1980). Experientially, then, death anxiety is typically not a part of conscious experience. A host of studies that have manipulated death awareness have provoked heightened death anxiety in subjects (e.g., Goldenberg et al., 2006; Greenberg et al., 1994; Pyszczynski, Greenberg, Solomon, Arndt, \& Schimel, 2004). Further, conscious death anxiety leads to active defenses such as distraction that specifically deal with the threatening material, serving to lower conscious death anxiety but doing little to manage unconscious death anxiety, which is manifested through other venues (Greenberg et al., 1994; Jost et al., 2007).

Self-regulation processes-namely, the ability to set up boundaries and exert will, including self-control and inhibitory capacity-defend against the threat of death and the experience of death anxiety. Studies have shown that ongoing management of thoughts of death fatigue self-regulatory mechanisms and thus heighten death anxiety over time (Gaillot, Schmeichel, \& Baumeister, 2006). Development of self-esteem, associated with positive affect, assists in preventing overt manifestations of death anxiety (Pyszycynski et al., 2004). Self-esteem is a culturally derived construct that is dependent on social validation, essentially defensive in nature, and functions to protect against core human fears (Pyszycynski et al., 2004). High self-esteem has been associated with cultural belongingness, which in turn buffers against death anxiety (Pyszycynski et al., 2004; Tomer, 1992).

Developmental. The expression of death anxiety varies according to developmental stage. Developmental theorists emphasize the life journey as a healthy, vital process with specific age-appropriate identity crises that lead to ego strength and maturation when resolved (Erikson, 1959; Fortner \& Neimeyer, 1999). Identity crises increase death anxiety in undergraduate college males (Sterling \& Van Horn, 1989), indicating the influence of developmental stage. Identity crises are characterized by high apprehension and uncertainty, with self-relevant transformations pending. Death anxiety is high among students in moratorium status, a state 
where individuals are actively exploring and trying to overcome identity issues in significant areas of their lives. Students who had formally experienced an identity crisis (identity achievement status) and those who had not experienced an identity crisis (foreclosure and diffusion statuses) had lower levels of death anxiety (Sterling \& Van Horn, 1989). Foreclosure status is when an individual has made an identity commitment without attempting identity exploration. Diffusion status occurs when there is neither an identity crisis or commitment (Erikson, 1959). Erikson's work on life span developmental tasks predicted that death awareness in midlife generates a crisis labeled generativity versus stagnation and in old age a crisis labeled as ego integrity versus despair (Fortner \& Neimeyer, 1999). During the midlife developmental stage of generativity versus stagnation, individuals' lifework is primary, and a significant life task is to perpetuate and transmit cultural values to family and community. During the older age stage of ego integrity versus despair, individuals look back on their lives to find meaningfulness and are concerned with wider mankind. Research on death anxiety has corroborated evidence for Erikson's developmental theory that death anxiety is negatively related to perceptions of life satisfaction, meaning, and purpose among both middle-aged and older subjects (Fortner \& Neimeyer, 1999).

Later life death anxiety has been attributed to early experiences in life regarding the withholding of emotional comfort and nourishment and anxieties induced by separation (Bassett, 2007). Firestone (in Bassett, 2007) theorized that infants ward off anxiety by generating a fantasy bond to the mother that is a source of connection that guards against separateness. Through development, personal death replaces the earlier neglect as the main source of anxiety. As a result, individuals who experience early life separation and neglect avoid authentic emotional bonds with others and may adopt a cynical stance about life and death in adulthood. Firestone (1993) thus proposed that death anxiety is related to the degree of individuation and self-actualization. Death anxiety increases as people give up primal defenses, reach new levels of self, and broaden their lives and personal prowess (Firestone, 1993). Firestone integrates existential and psychoanalytic thought to explain how people adapt to death anxiety through progressive self-denial and addictive attachments, giving up life in face of future death. In essence, as life becomes more meaningful and valued, death anxiety increases because the affective investment in one's existence multiplies (Firestone, 1993).

Age has been shown to be a significant factor in the perception of death anxiety (Russac, Gatliff, Reece, \& Spottswood, 2007). Robbins, Lloyd, Carpenter, and Bender (1992) found that younger staff members in a long-term-care facility had higher levels of death anxiety and practical anxiety about managing the dying. Conversely, high death anxiety among elderly adults has been related to physical and psychological problems and low ego integrity (Fortner \& Neimeyer, 1999). Research has shown that death anxiety is higher among the middle-aged, declines during later adulthood, and then stabilizes in old age (Fortner \& Neimeyer, 1999). Cicirelli (2006) found that middle-aged to older individuals experienced greater death anxiety because of discrepancies between their desired and expected time left to live. Thus, there may be important differences in conscious awareness of death anxiety concomitant with different age level-specific developmental tasks. 
Sociocultural Shaping. Experiential, cognitive, and perhaps emotional dimensions of death anxiety are shaped by and hence may vary by culture. A primary responsibility of culture is to provide protection against knowledge and fear of death (Becker, 1973). Cultural protection is manifested symbolically in a blend of learned and shared meanings and beliefs, many of which originate in conventional religious dogma and ritual (Becker, 1973; Schumaker, Barraclough, \& Vagg, 1988). Kübler-Ross (2002) noted that cultures differ in their ways of articulating and giving meaning to death, and some cultures are more effective in allaying side effects associated with death awareness. Western societies are often reproached for concealing the sick and elderly from view, thus protecting their members from death awareness (Schumaker et al., 1988). Such practices could increase death anxiety because death becomes an unusual phenomenon detached from the natural order of events (Schumaker et al., 1988). Denial is the prevalent death attitude in America, and death anxiety is avoided via an elaborate system that offers few reminders of disability, aging, illness, and death (Martz \& Livneh, 2003), suggesting that the cultural context shapes the cognitive, experiential, and possibly emotional components of death anxiety. While little research has examined death anxiety in non-White ethnic and racial groups in the United States, one study found that older African Americans had different death-related concerns than Whites when compared on multidimensional cognitive factors (DePaola et al., 2003).

In non-Western cultures, Abdel-Khalek (1991) found little difference in death anxiety scores among Egyptian students compared with other cultures using Templer's death anxiety scale. Schumaker, Warren, and Groth-Marnat (1991) found higher death anxiety among Japanese males compared to Australian males, suggesting fewer defensive postures toward death among Japanese males. Women may also have different sociocultural experiences and cultural conditioning than men. For example, studies have found that female gender has been associated with higher death anxiety in adolescent populations and in cross-cultural research (Adbel-Khalek, 1991, 2004, 2005; Cotter, 2003; Pierce, 2007; Singh Madnawat, \& Singh Kachhawa, 2007). In a large sample of older individuals aged 61 to 80 years, elderly females were shown to have significantly higher death anxiety than males (Hickson, Housley, \& Boyle, 1988).

The role of culture in assuaging the major human concern surrounding death has led to terror management theory, a theory backed by research that has examined the role of dominant cultural beliefs and values in modifying death terror (Becker, 1973; Greenberg et al., 1994; Pyszczynski et al., 2004). Self-esteem has been shown to buttress against death anxiety in this research (Pyszczynski et al., 2004). Kastenbaum (1996) identified the role of sociocultural adherence in stifling death anxiety and asserted that death anxiety is even relevant at the level of legislative arenas and corporate meeting places. This death anxiety is concerned with managing "the ambiguities, uncertainties, and options that are arising as life and death move with us into the postmodern world" (Kastenbaum, 1996, p. 114).

Source of Motivation. Death anxiety is a source of motivation. Because death anxiety is fundamental and universal to the human condition, occurs after the individual is able to conceptualize death as a complex symbol, and is largely denied or repressed, 
its symbolic expression is often manifest by artistic creativity and accumulation of resources, or efforts aimed at overcoming death symbolically (Becker, 1973; Landau, Greenberg, Solomon, Pyszczynski, \& Martens, 2006). The source of motivation may emerge as an expression of the tension between our actual conditions as temporal, restricted beings and human aspirations to be unlimited, immortal beings (Momeyer, 1988). Converging evidence supports that psychological defenses against death anxiety are a source of motivating impetus for a variety of human behaviors (Bassett, 2007). Reminders of death lead to increased striving for self-esteem, adherence to group norms, support for charismatic political candidates, and derogation of individuals, political groups, and artwork that does not fit into a particular cultural view (Bassett, 2007; Jost et al., 2007; Landau et al., 2006).

\section{Measurement of DeAth AnXiety}

Death anxiety has been measured using largely self-report measures. Templer's (1970) 15-item Death Anxiety Scale (DAS) has been used most frequently to measure death anxiety (Abdel-Khalek, 1991, 2005; Abdel-Khalek, Beshai, \& Templer, 1993; Abdel-Khalek \& Omar, 1988; Donovan, 1993; Lester \& Castromayor, 1993; Ray \& Raju, 2006; Schumaker et al., 1988). The DAS is shown to be based on a two-factor model of death anxiety that includes psychological (internal) and life experience (external) factors related to death (Tomer, 1992). The DAS, based on Templer's doctoral thesis, has resulted in a multitude of death anxiety studies in both Western and Mideastern contexts with healthy college-aged samples. Beshai and Naboulsi (2004) noted that Templer's well-validated DAS is translated into 26 languages but was developed in an environmental context that was atheoretical.

The 20-item Death Anxiety Inventory, developed and validated for a Spanish population, is modeled on Templer's two-factor scale and was tested on health care professionals who work with people facing death (Gómez, Hidalgo, \& Tomás-Sábado, 2007; Tomás-Sábado \& Gómez-Benito, 2005). The 25-item Revised Death Anxiety Scale is an age-sensitive measure that provides a means of assessing differences and comparisons between and within groups (Thorson \& Powell, 1992).

Other scales include the Collett-Lester Fear of Death of Self Scale, which measures fear of death at the conscious level (Kraft et al., 1987). Spilka's Death Perspective Scale assesses eight death stances, including "death as pain and loneliness, death as afterlife-of-reward, death as forsaking dependents plus guilt, death as courage, death as failure, and death as natural end" (Smith et al., 1983-1984). The Death Anxiety Questionnaire is a 15-item self-report measure that has been used in populations facing life-threatening illness (Cella \& Tross, 1987).

Death anxiety has been measured as a multidimensional construct with the Multidimensional Fear of Death Scale, a 48-item measure containing eight subscales that has documented reliability and validity (e.g., DePaola et al., 2003; Neimeyer \& Moore, 1994). Because death anxiety may be implicit or nonconscious, researchers have used Palm Pilot versions of the Implicit Association Test measuring death perceptions testing death valence (bad vs. good), death anxiety (anxious vs. calm), and denial (others vs. self) (Bassett \& Dabbs, 2003). The Children's Apperception 
Test, a measure that was developed to learn about cognitive structures, defenses, and dynamic ways of reacting to threat, has also been used to assess death anxiety in children facing life-threatening and non-life-threatening illness (Lee, Lieh-Mak, Hung, \& Luk, 1983-1984).

Death anxiety has been examined by inducing a mortality salient condition (Gailliot et al., 2006; Greenberg et al., 1994). In this regard, individuals are primed with death-related personal contents and are asked to go deeper into their feelings about their own or a loved one's death. Participant's respond to open-ended questions about their fears about their own or a loved one's death and complete mood assessments.

\section{Definition of DeAth ANXIETy}

Carpenito-Moyet (2008), in the Handbook of Nursing Diagnosis, defines death anxiety as "the state in which an individual experiences apprehension, worry, or fear related to death and dying" (p. 39). In the Nursing Outcomes Classification guide, death anxiety is defined as "vague uneasy feeling of discomfort or dread generated by perceptions of a real or imagined threat to one's existence" (Moorhead et al., 2008, p. 761).

While the terms are mostly used synonymously, the concepts "death anxiety" and "fear of death" have also been distinguished. Death anxiety refers to a dread of complete annihilation, whereas fear of death is a more concrete belief that death is frightening (Momeyer, 1988). Cicirelli (2006) identified that dread of annihilation is related more broadly to a mental or spiritual awareness of the loss of existence, whereas fear of death is related to the physical awareness of loss of existence. Importantly, biological research has shown that anxiety and fear are separate constructs that arise from separate but proximal and related anatomical structures. Anxiety has been more closely associated with septo-hippocampal system activation with pathways that extend to higher cortical regions (Gray, 1985). Fear relates more specifically to the activation of the amygdaloid complex, a system characterized by a survival-oriented, automatic rapid reaction (Larson et al., 2006). While there are anatomical distinctions in origin between fear and anxiety systems, how these phenomena are experienced in the human, particularly in the management of major ongoing survival-oriented threats, are intertwined. The two systems may be activated simultaneously, but the fast survival-oriented threat system is instantly achieved at the preconscious level (LeDoux, 2008).

Given the critical role that culture (a cognitive-structural construct) plays in allaying death fear, death anxiety researchers (Becker, 1973; Greenberg et al., 1994) do not distinguish between death anxiety and fear. Death anxiety has been referred to as a pervasive fear of nonexistence, or as a fear of experiencing nonbeing (Christian, 1981). Yalom (1980), who also views anxiety and fear about death synonymously, defined death anxiety as a "dread of death that resides in the unconscious, a dread that is formed early in life at a time prior to the development of precise conceptual formation, a dread that is terrible and inchoate and exists outside of language and image" (p. 189). Based on the attributes that were identified in this comprehensive review, death anxiety is a multidimensional 
construct related to fear of and anxiety related to the anticipation and awareness of the reality of dying and death that includes emotional, cognitive, and motivational components that vary by developmental stage and sociocultural life occurrences. Given the comprehensive nature of the ongoing management of the awareness of death in the human, it becomes apparent that death anxiety encompasses both fear and anxiety emotional components. Further, death anxiety is not necessarily consciously manifested.

\section{ANTECEDENTS}

Death anxiety is initiated by an increased awareness of death salience (reminders of personal mortality). Characteristics may overlap and cluster in three identified categories: stressful environments such as war or the experience of unpredictable circumstances, diagnosis of a life-threatening illness or the experience of a lifethreatening event, and experiences with death and dying.

Stressful Environments. Abdel-Khalek (1991), using Templer's DAS, identified that long-term habituation to insecure stressful environments, such as chronic civil war, may over time decrease levels of death anxiety in a population. For example, death anxiety levels were measured in seven samples of Kuwaiti college undergraduates from 1988 to 2002, covering the interval both before and after the Iraqi invasion of Kuwait (Abdel-Khalek, 2004). The findings demonstrated significant increases in death anxiety scores for three testings following the Iraqi invasion, a time characterized by increased violence and the loss of human rights, and again following liberation from the Iraqis, a time characterized by transition (AbdelKhalek, 2004). In another study, Egyptian nursing students demonstrated higher death anxiety than a similar group of Spanish nursing students (Abdel-Khalek \& Tomás-Sábado, 2005). This is significant because, compared to Spain, Egyptian society has a comparatively lower per capita income and more stress as part of a developing country and culturally is preoccupied with mourning and bereavement (Abdel-Khalek \& Tomás-Sábado, 2005).

While environmental factors, particularly stressful and unpredictable contexts, may impact the experience of death anxiety, this may not always be so. In a large study conducted among young college students in the United States using the Multidimensional Fear of Death Scale (Neimeyer \& Moore, 1994), little difference was found in overall death anxiety between students who reported major traumatic experiences, such as a serious motor vehicle crash, and those who did not (Floyd, Coulon, Yanez, \& Lasota, 2005). College students who watched 1-minute video clips of traumatic death events experienced death anxiety using Templer's DAS only as a main effect for the video duration (Ryburn \& Festa, 2006). The findings suggest that conscious manifestations of death anxiety may fluctuate in the face of stressors among individuals based on the type, context, and duration of environmental trauma and death-related stressors.

Diagnosis of a Life-Threatening Illness. Researchers have examined whether life-threatening illness is associated with heightened death anxiety. Among young men treated for either testicular cancer or Hodgkin's disease, death anxiety was 
higher among the more recently diagnosed men using the 15-item Fear of Death Questionnaire (Cella \& Tross, 1987). Contextual issues surrounding serious illness, such as concerns related to having loved ones witness the dying process and leaving loved ones behind, were also associated with increased death anxiety (Cella \& Tross, 1987).

Patients with brain tumors and their families were preoccupied with death anxiety and existential thoughts in qualitative analyses of interview data (Adelbratt \& Strang, 2000). Patients lived with a constant sense of threat and tried to avoid death thoughts during their daily lives, but symptoms would activate death anxiety (Adelbratt \& Strang, 2000). In terminally ill patients, death anxiety was relatively low, suggesting that realistic acceptance and coming to terms with the inevitability of death had occurred using the Fear of Death Scale (Smith et al., 1983-1984). Certainty of beliefs toward an afterlife of reward was a significant finding in this study (Smith et al., 1983-1984). A longitudinal study that focused on human immunodeficiency virus (HIV) status and death anxiety among males found the highest levels of death anxiety among the group who were both HIV positive and symptomatic (Catania, Turner, Choi, \& Coates, 1992). Social support became particularly important as the men approached death, and interpersonal interaction may have alleviated death anxiety (Catania et al., 1992).

Experiences With Death and Dying. Studies have explored the role that death experiences play in generating death anxiety. Among adolescents who had experienced the death of a grandparent, grief due to bereavement was the only significant predictor of death anxiety (Ens \& Bond, 2005).

Using an implicit test that measured death valence, anxiety, and denial in addition to a death anxiety scale, funeral studies students were shown to have lower explicit death anxiety and implicit death denial than general university students (Bassett \& Dabbs, 2003). The study suggests that explicit death anxiety measures may underreport death anxiety experience and that educational exposures of the funeral students may reduce death denial (Bassett \& Dabbs, 2003). The findings of variation between implicit and explicit death anxiety underscore the importance of construct attributes that may exist outside conscious awareness.

More experienced nursing students report higher death anxiety than do their less experienced counterparts (Chen, Del Ben, Fortson, \& Lewis, 2006). Critical care nurses reported significantly more death anxiety, burnout, and stress compared with hospice nurses (Mallett, Price, Jurs, \& Slenker, 1991). Similarly, Payne, Dean, and Kalus (1998) found lower death anxiety and heightened recall of both positive and challenging patient care experiences among hospice nurses. Hospice philosophy approaches death as an essential component of living and, as such, openly confronts the issues associated with death's presence. A study examined the effects of palliative care training and death anxiety in palliative care volunteers. Topics such as spiritual issues from a multifaith and multicultural background, communication, the dying process, and grief and bereavement were included. While death anxiety scores did not change before and following training, participants felt better prepared and more competent to manage situations of clients facing terminal illness and death in this study (Claxton-Oldfield, Crain, \& Claxton-Oldfield, 2007). 


\section{Consequences of DeAth AnXIETy}

Consequences of death anxiety cluster around adaptive and maladaptive presentations.

Adaptive Consequences. Numerous studies have shown that when death awareness and its associated anxiety are increased, individuals respond by defending and/or intensifying their cultural beliefs (Pyszczynski et al., 2004). In Western cultures, the pursuit and possession of material objects, or materialism, could also be a coping response to death anxiety (Arndt, Solomon, Kasser, \& Sheldon, 2004; Rindfleisch \& Burroughs, 2004). Collective endorsement of brands and consumerism may provide a sense of meaning, strengthen social ties and belonging, and enhance perceptions of power in achieving important life accomplishments. This in turn may improve self-worth and status perceptions, factors that insulate against death awareness and death anxiety (Rindfleisch \& Burroughs, 2004).

Other research has found that death awareness and anxiety increase the sense of commitment in romantic relationships (Mikulincer, Florian, \& Hirschberger, 2003). The researchers theorize that close relationships function as a death anxiety buffer, similar to self-esteem and cultural worldview (Mikulincer et al., 2003). A series of studies examined whether death anxiety underlies emotional reactions toward individuals with disabilities (Hirschberger, Florian, \& Mikulincer, 2005). Findings showed that males responded to death anxiety by withdrawing emotion and compassion, whereas females responded by increasing compassionate responses (Hirschberger et al., 2005). Death primes may motivate men and women to behave in culturally prescribed gender-stereotyped ways. Thus, males who have heightened death anxiety may respond with less compassion because they are socialized to display strength and to value independence and instrumentality. Females may be socialized to be responsive to the needs of others and to show concern and care (Hirschberger et al., 2005). Positive consequences of death anxiety experience may include new learning and growth, acceptance, enhanced life meaning, and the pursuit of an authentic existence (Firestone, 1993).

Maladaptive Consequences. While death anxiety is both normal and universal, a significant consequence may be mental health problems. Death anxiety has been associated with heightened negative attitudes toward the elderly and anxiety toward aging (DePaola, Neimeyer, Lupfer, \& Fiedler, 1992). Death anxiety has been found to predict posttraumatic stress reactions in individuals with spinal cord injuries (Martz, 2004). These individuals were less likely to have a future time orientation, suggesting an avoidance of projecting into the future the fact that death is inevitable with the lapse of time (Martz \& Linveh, 2003). Death anxiety is also associated with eating and self-mutilation disorders (Farber, Jackson, Tabin, \& Bachar, 2007; Jackson, Davidson, Russell, \& Vandereycken, 1990). Death anxiety was found to be significantly higher among both males and females with clinical anxiety disorders when compared to nonclinical, schizophrenic, and addicted groups (Abdel-Khalek, 2005). It is thought that generalized anxiety and death anxiety share variance in that both hold negative emotions, characterized by worry, distress, insecurity, tension, and uneasiness, whether directed toward the threat of death or more general 
dangers (Abdel-Khalek, 2005). Further, death anxiety may lead to ambivalence toward the body, disruption in personal relationships, and withdrawal from sexual intimacy because the physical body serves as a reminder of death (Bassett, 2007; Goldenberg et al., 2006). More research is needed to determine if death anxiety increases as a result of existing psychiatric conditions or is a precursor to psychiatric conditions.

Nurses with higher death anxiety may be reluctant to discuss death issues with patients and their families (Deffner \& Bell, 2005). Nurses who receive education in communication related to death become more comfortable with discussion of death concerns with patients and their families, suggesting the importance of death anxiety awareness in nursing education curriculum (Deffner \& Bell, 2005).

\section{DISCUSSION}

The purpose of this article was to review the health-related literature on death anxiety to identify the defining attributes, antecedents, and consequences of the concept. Results from this concept analysis demonstrate that important attributes of death anxiety include emotion; cognitive, experiential, developmental, and sociocultural shaping; and source of motivation. Antecedents of death anxiety include stressful environments and the experience of unpredictable circumstances, diagnosis of a life-threatening illness or the experience of a life-threatening event, and experiences with death and dying. Consequences of death anxiety include both adaptive and maladaptive presentations. The results of the concept analyses are important because while a broad literature on death anxiety exists, little integration and synthesis of the construct has occurred.

\section{Clinical IMPLications}

The concept of death anxiety has far-reaching importance to nursing practice. As direct care providers and as educators, nurses are in a critical position to make an impact in the area of death anxiety. Because individuals with death anxiety may manifest behaviors that suppress the problem, the importance of assessing for death anxiety among individuals with psychological distress and behavioral problems is paramount (Yalom, 1980). It is essential that nurses consider death anxiety as a possible contributor as well as a possible source for therapeutic intervention in a variety of clinical presentations and contexts (e.g., depression, substance abuse, life-threatening illness or injury, eating disorders, emergency room visits). In addition, palliative goals for terminally ill patients, such as ensuring quality end-of-life care and good death, embrace the necessity of assessment and management of death anxiety.

A second area of clinical importance relates to nurses' own death anxiety as they face death, pain, and suffering in their clinical practice. Death anxiety in nurses may impede therapeutic interactions with individuals at the end of life who are facing death (Deffner \& Bell, 2005; Gómez et al., 2007). Further, unresolved death anxiety 
may result in heightened stress and burnout in nurses (Mallett et al., 1991). Health care workers may find it difficult to talk about death with their patients (Robbins et al., 1992). Nurse educators and managers must consider the importance of death anxiety in the development of nursing curriculum and policy. Further, support for nurses to find therapeutic motivational avenues for expressing death anxiety is paramount.

In Handbook of Nursing Diagnosis, Carpenito-Moyet (2008) cites specific nursing interventions for death anxiety. The generic nursing interventions are focused on managing the real concrete spectrum of death and include such interventions as exploring and encouraging activities that involve life stories, relationships, personal interpretations of spirituality, advance directives, and symptom management. These interventions are oriented toward persons who are facing actual imminent death. The research on death anxiety demonstrates that the concept affects many individuals who are physically healthy but who are vulnerable because of stressful environments and the experience of unpredictable circumstances, experiences with life-threatening events, and experiences with death and dying among known loved ones. The importance of nursing assessment for the possibility of death anxiety cannot be underestimated. Recognizing this phenomenon may assist healthy individuals in directing their lives toward life-enhancing fulfillment. Further, the findings demonstrate the necessity of targeting interventions aimed at managing death anxiety and its repercussions toward varying developmental stages in healthy individuals.

\section{RESEARCH IMPLICATIONS}

The findings from this concept analysis of death anxiety point to several areas for further research. Death anxiety is not a new concept in nursing, but research on the topic has not kept pace with the enormous spectrum of nursing influence in both preventive and acute care settings. Most of the interest in death issues in nursing has been generated by palliative care and hospice practice. Death anxiety may need more critical attention in acute care settings where the focus is on active treatment and curative management. Further, recognition of the relevance of death anxiety as an important phenomenon among healthy individuals is also of essence.

Measurement of death anxiety remains in its developing phases (Beshai \& Neboulsi, 2004; Gómez et al., 2007; Levin, 1989-1990; Neimeyer \& Moore, 1994). Assessment and measurement of the concept would be enhanced by the addition of qualitative measures designed to capture individualized personal constructs related to death anxiety (Beshai \& Neboulsi, 2004). Often death anxiety is implicit; thus, incorporating tools to assess for this phenomenon must tap for underlying presence. Because death anxiety presentation may vary among individuals at different developmental stages in life and circumstance, assessment is critical. Nursing research that examines death anxiety and personal self-esteem among nursing personnel based on age, gender, culture of origin, personal experiences, and nursing background is warranted. Further, research is needed to develop targeted nursing interventions that would reduce the maladaptive consequences associated with death anxiety. 


\section{THEORETICAL IMPLICATIONS}

This concept analysis of death anxiety was based on the evolutionary method of concept analyses developed by Rodgers. The concept of death anxiety is of relevance to the science of nursing, and this analysis serves as a beginning foundation by providing a theoretical definition of the concept. This concept analysis on death anxiety is limited in time and context; hence, ongoing developmental work is needed to expand a conceptual framework of death anxiety for the discipline of nursing now and in the future.

\section{REFERENCES}

Abdel-Khalek, A. M. (1991). Death anxiety among Lebanese samples. Psychological Reports, 68, 924-926.

Abdel-Khalek, A. M. (2004). Does war affect death anxiety level? Seven readings of measurements (1988-2002) before and after the Iraqi invasion of Kuwait. Omega, 49, 287-297.

Abdel-Khalek, A. M. (2005). Death anxiety in clinical and non-clinical groups. Death Studies, 29, 251-259.

Abdel-Khalek, A. M., Beshai, J. A., \& Templer, D. I. (1993). The structure of Templer's Death Anxiety Scale among Egyptian students. Psychological Reports, 72, 920-922.

Abdel-Khalek, A. M., \& Omar, M. M. (1988). Death anxiety, state and trait anxiety in Kuwaitian samples. Psychological Reports, 63, 715-722.

Abdel-Khalek, A. M., \& Tomás-Sábado, J. (2005). Anxiety and death anxiety in Egyptian and Spanish nursing students. Death Studies, 29, 157-169.

Adelbratt, S., \& Strang, P. (2000). Death anxiety in brain tumour patients and their spouses. Palliative Medicine, 14, 499-507.

Alvarado, K. A., Templer, D. I., Bresler, C., \& Thomas-Dobson, S. (1995). The relationship of religious variables to death depression and death anxiety. Journal of Clinical Psychology, 51, 202-204.

Arndt, J., Solomon, S., Kasser, T., \& Sheldon, K. (2004). The urge to splurge: A terror management account of materialism and consumer behavior. Journal of Consumer Psychology, $14,198-212$.

Bassett, J. F. (2007). Psychological defenses against death anxiety: Integrating terror management theory and Firestone's separation theory. Death Studies, 31, 727-750.

Bassett, J. F., \& Dabbs, J. M. (2003). Evaluating explicit and implicit death attitudes in funeral and university students. Mortality, 8, 352-371.

Becker, E. (1973). The denial of death. New York: Free Press.

Benton, J. P., Christopher, A. N., \& Walter, M. I. (2007). Death anxiety as a function of aging anxiety. Death Studies, 31, 337-350.

Beshai, J. A., \& Naboulsi, M. A. (2004). Existential perspectives on death anxiety. Psychological Reports, 95, 507-513.

Carpenito-Moyet, L. J. (2008). Handbook of nursing diagnosis. Philadelphia: Lippincott, Williams and Wilkins.

Catania, J. A., Turner, H. A., Choi, K. H., \& Coates, T. J. (1992). Coping with death anxiety: Help-seeking and social support among gay men with various HIV diagnoses. AIDS, 6, 999-1005.

Cella, D. F., \& Tross, S. (1987). Death anxiety in cancer survival: A preliminary cross-validation study. Journal of Personality Assessment. 51, 451-461. 
Chen, Y., Del Ben, K. S., Fortson, B. L., \& Lewis, J. (2006). Differential dimensions of death anxiety in nursing students with and without nursing experience. Death Studies, 30, 919-929.

Christian, J. L. (1981). Philosophy: An introduction to the art of wondering. New York: Holt, Rinehart and Winston.

Cicirelli, V. G. (2006). Fear of death in mid-old age. Journal of Gerontology, 61, 75-81.

Claxton-Oldfield, S., Crain, M., \& Claxton-Oldfield, J. (2007). Death anxiety and death competency: The impact of a palliative care volunteer training program. American Journal of Hospice and Palliative Medicine, 23, 464-468.

Cotter, R. P. (2003). High risk behaviors in adolescence and their relationship to death anxiety and death personifications. Omega, 47, 119-137.

Deffner, J. M., \& Bell, S. K. (2005). Nurses' death anxiety, comfort level during communication with patients and families regarding death, and exposure to communication education: A quantitative study. Journal for Nurses in Staff Development, 21, 19-23.

DePaola, S. J., Griffin, M., Young, J. R., \& Neimeyer, R. A. (2003). Death anxiety and attitudes towards the elderly among older adults: The role of gender and ethnicity. Death Studies, $27,335-54$.

DePaola, S. J., Neimeyer, R. A., Lupfer, M. B., \& Fiedler, J. (1992). Death concern and attitudes toward the elderly in nursing home personnel. Death Studies, 16, 537-555.

Donovan, J. M. (1993). Validation of a Portuguese form of Templer's Death Anxiety Scale. Psychological Reports, 73, 195-200.

Erikson, E. H. (1959). Identity and the life cycle. New York: International Universities Press.

Ens, C., \& Bond, J. B. (2005). Death anxiety and personal growth in adolescents experiencing the death of a grandparent. Death Studies, 29, 171-178.

Farber, S. K., Jackson, C., Tabin, J. K., \& Bachar, E. (2007). Death and annihilation anxieties in anorexia nervosa, bulimia, and self-mutilation. Psychoanalytic Psychology, 24, 289-305.

Firestone, R. W. (1993). Individual defenses against death anxiety. Death Studies, 17, 497-515.

Floyd, M., Coulon, C., Yanez, A. P., \& Lasota, M. T. (2005). The existential effects of traumatic experiences: A survey of young adults. Death Studies, 29, 55-63.

Fortner, B. V., \& Neimeyer, R. A. (1999). Death anxiety in older adults: A quantitative review. Death Studies, 23, 387-411.

Gaillot, M. T., Schmeichel, B. J., \& Baumeister, R. F. (2006). Self-regulatory processes defend against the threat of death: Effects of self-control depletion and trait self-control on thoughts and fears of dying. Journal of Personality and Social Psychology, 91, 49-62.

Glas, G. (2007). Anxiety, anxiety disorders, religion, and spirituality. Southern Medical Journal, $100,621-625$.

Goldenberg, J. L., Hart, J., Pyszczynski, T., Warnica, G. M., Landau, M., \& Thomas, L. (2006). Ambivalence toward the body: Death, neuroticism, and the flight from physical sensation. Personality and Social Psychology Bulletin, 32, 1264-1277.

Gómez, J., Hidalgo, D., \& Tomás-Sábado, J. (2007). Using polytomous item response models to assess death anxiety. Nursing Research, 56, 89-96.

Gray, J. A. (1985). The neuropsychology of anxiety. Issues in Mental Health Nursing, 7, 201-222.

Greenberg, J., Pyszczynski, T., Solomon, S., Simon, L., \& Breus, M. (1994). Role of consciousness and accessibility of death-related thoughts in mortality salience effects. Journal of Personality and Social Psychology, 67, 627-637.

Hickson, J., Housley, W. F., \& Boyle, C. (1988). The relationship of locus of control, age, and sex to life satisfaction and death anxiety in older persons. International Journal of Aging Human Development, 26, 191-198.

Hirschberger, G., Florian, V., \& Mikulincer, M. (2005). Fear and compassion: A terror management analysis of emotional reactions to physical disability. Rehabilitation Psychology, 50, 246-257. 
Jackson, C., Davidson, G., Russell, J., \& Vandereycken, W. (1990). Ellen West revisited: The theme of death in eating disorders. International Journal of Eating Disorders, 9, 529-536.

Jost, J. T., Napier, J. L., Thorisdottir, H., Gosling, S. D., Palfai, T. P., \& Ostafin, B. (2007). Are needs to manage uncertainty and threat associated with political conservatism or ideological extremity? Personality and Social Psychology Bulletin, 33, 989-1007.

Kastenbaum, R. (1996). A world without death? First and second thoughts. Mortality, 1, 111-121.

Kelly, G. A. (1955). The psychology of personal constructs (Vol. 1). New York: Norton.

Knight, K. H., \& Elfenbein, M. H. (1993). Relationship of death education to the anxiety, fear, and meaning associated with death. Death Studies, 17, 411-425.

Kraft, W. A., Litwin, W. J., \& Barber, S. E. (1987). Religious orientation and assertiveness: Relationship to death anxiety. Journal of Social Psychology, 127, 93-95.

Kübler-Ross, E. (2002). On death and dying; Questions and answers on death and dying; On life after death. New York: Quality Paper Book Club.

Landau, M. J., Greenberg, J., Solomon, S., Pyszczynski, T., \& Martens, A. (2006). Windows into nothingness: Terror management, meaninglessness, and negative reactions to art. Journal of Personality and Social Psychology, 90, 879-892.

Larson, C. L., Schaefer, H. S., Siegle, G. J., Jackson, C. A. B., Anderle, M. J., \& Davidson, R. J. (2006). Fear is fast in phobic individuals: Amygdala activation in response to fear-relevant stimuli. Biological Psychiatry, 60, 410-417.

LeDoux, J. (1996). The emotional brain. New York: Simon \& Schuster.

LeDoux, J. (2008). Remembrance of emotions past. In K. Fischer \& M. H. Immordino-Yang (Eds.), The Jossey-Bass reader on the brain and learning (pp. 151-179). San Francisco: Jossey-Bass.

Lee, P. W., Lieh-Mak, F., Hung, B. K., \& Luk, S. L. (1983-1984). Death anxiety in leukemic Chinese children. International Journal of Psychiatric Medicine, 13, 281-289.

Lester, D., \& Castromayor, I. (1993). The construct validity of Templer's death anxiety scale in Filipino students. The Journal of Social Psychology, 133, 113-114.

Levin, R. (1989-1990). A re-examination of the dimensionality of death anxiety. Omega, 20, 341-349.

Lonetto, R. (1982). Personifications of death and death anxiety. Journal of Personality Assessment, 46, 404-408.

Lonetto, R., Mercer, G. W., Fleming, S., Bunting, B., \& Clare, M. (1980). Death anxiety among university students in Northern Ireland and Canada. Journal of Psychology, 104, 75-82.

Lonetto, R., \& Templer, D. I. (1986). Death anxiety. Washington, DC: Hemisphere Publishing.

Mallett, K., Price, J. H., Jurs, S. G., \& Slenker, S. (1991). Relationships among burnout, death anxiety, and social support in hospice and critical care nurses. Psychological Reports, 68, $1347-1359$.

Martz, E. (2004). Death anxiety as a predictor of posttraumatic stress levels among individuals with spinal cord injuries. Death Studies, 28, 1-17.

Martz, E., \& Livneh, H. (2003). Death anxiety as a predictor of future time orientation among individuals with spinal cord injuries. Disability and Rehabilitation, 25, 1024-1032.

McDonald, R. T., \& Hilgendorf, W. A. (1986). Death imagery and death anxiety. Journal of Clinical Psychology, 42, 87-91.

Mikulincer, M., Florian, V., \& Hirschberger, G. (2003). The existential function of close relationships: Introducing death into the science of love. Personality and Social Psychology Review, 7, 20-40.

Momeyer, R. W. (1988). Confronting death. Indianapolis: Indiana University Press.

Moorhead, S., Johnson, M., Maas, M. L., \& Swanson, E. (2008). Nursing outcomes classification (NOC). St. Louis, MO: Mosby Elsevier. 
Morrow, F. R. M. (2007). Death anxiety: Living your dying: A theoretical and heuristical study of the anxiety of death and the sacred. Dissertation Abstracts International, 67(10)6070B. (UMI No. 3238863).

Neimeyer, R. A. (1994). Death anxiety handbook: Research, instrumentation, and application. Washington, DC: Taylor \& Francis.

Neimeyer, R. A., \& Moore, M. K. (1994). Validity and reliability of the multidimensional fear of death scale. In R. A. Neimeyer (Ed.), Death anxiety handbook: Research, instrumentation, and application (pp. 103-117). Washington, DC: Taylor \& Francis.

Neimeyer, R. A., Wittkowski, J., \& Moser, R. P. (2004). Psychological research on death attitudes: An overview and evaluation. Death Studies, 28, 309-340.

Nyatanga, B. \& de Vocht, H. (2006). Towards a definition of death anxiety. International Journal of Palliative Nursing, 12, 410-413.

Öhman, A. (2000). Fear and anxiety: Evolutionary, cognitive, and clinical perspectives. In M. Lewis \& J. M. Haviland-Jones (Eds.), Handbook of emotions (pp. 573-593). New York: Guilford.

Panksepp, J. (1998). Affective neuroscience: The foundations of human and animal emotions. New York: Oxford University Press.

Payne, S. A., Dean, S. J., \& Kalus, C. (1998). A comparative study of death anxiety in hospice and emergency nurses. Journal of Advanced Nursing, 28, 700-706.

Pierce, J. D. (2007). Gender differences in death anxiety and religious orientation among U.S. high school and college students. Mental Health, Religion, and Culture, 10, 143-150.

Pyszczynski, T., Greenberg, J., Solomon, S., Arndt, J., \& Schimel, J. (2004). Why do people need self-esteem? A theoretical and empirical overview. Psychological Bulletin, 130, 435-468.

Ray, R., \& Raju, M. (2006). Attitude towards euthanasia in relation to death anxiety among a sample of 343 nurses in India. Psychological Reports, 99, 20-26.

Rindfleisch, A., \& Burroughs, J. E. (2004). Terrifying thoughts, terrible materialism? Contemplations on a terror management account of materialism and consumer behavior. Journal of Consumer Psychology, 14, 219-224.

Robbins, I., Lloyd, C., Carpenter, S., \& Bender, M. P. (1992). Staff anxieties about death in residential settings for elderly people. Journal of Advanced Nursing, 17, 548-553.

Rodgers, B. L. (2000). Concept analysis: An evolutionary view. In B. L. Rodgers \& K. A. Knafl (Eds.), Concept development in nursing (pp. 77-102). Philadelphia: Saunders.

Russac, R. J., Gatliff, C., Reece, M., \& Spottswood, D. (2007). Death anxiety across the adult years: An examination of age and gender effects. Death Studies, 31, 549-561.

Ryburn, J., \& Festa, D. (2006). College students responses to traumatic events involving sudden death. Illness, Crisis, and Loss, 14, 143-158.

Schumaker, J. F., Barraclough, R. A., \& Vagg, L. M. (1988). Death anxiety in Malaysian and Australian university students. Journal of Social Psychology, 128, 41-47.

Schumaker, J. F., Warren, W. G., \& Groth-Marnat, G. (1991). Death anxiety in Japan and Australia. Journal of Social Psychology, 131, 511-518.

Singh Madnawat, A.V., \& Singh Kachhawa, P. (2007). Age, gender, and living circumstances: Discriminating older adults on death anxiety. Death Studies, 31, 763-769.

Smith, D. K., Nehemkis, A. M., \& Charter, R. A. (1983-1984). Fear of death, death attitudes, and religious conviction in the terminally ill. International Journal of Psychiatric Medicine, $13,221-232$.

Sterling, C. M., \& Van Horn, K. R. (1989). Identity and death anxiety. Adolescence, 24. $321-$ 326.

Templer, D. I. (1970). The construction and validation of a death anxiety scale. Journal of General Psychology, 82, 165-177. 
Thorson, J. A., \& Powell, F. C. (1992). A revised death anxiety scale. Death Studies, 16, 507-521.

Tolstoy, L. (1960). The death of Ivan Ilych and other stories. New York: NAL Penguin.

Tomás-Sábado, J., \& Gómez-Benito, J. (2005). Construction and validation of the Death Anxiety Inventory (DAI). European Journal of Psychological Assessment, 21, 108-114.

Tomer, A. (1992). Death anxiety in adult life, theoretical perspectives. Death Studies, 16, 475-506.

Tomer, A., \& Eliason, G. (1996). Toward a comprehensive model of death anxiety. Death Studies, 20, 343-365.

Walker, L. O., \& Avant, K. C. (1995). Strategies for theory construction in nursing. Norwalk, CT: Appleton and Lange.

Yalom, I. D. (1980). Existential psychotherapy. New York: Basic Books.

Zeyrek, E. Y. (2006). Death anxiety and a Taoist orientation in two cultures. Perceptual and Motor Skills, 103, 70-78.

Acknowledgments. The study was supported by NINR T32 NR 0704 funding.

Correspondence regarding this article should be directed to Rebecca Helen Lehto, PhD, Michigan State University, College of Nursing, Owen Graduate Center, W-138, East Lansing, MI 48824-1317. E-mail: rebecca.lehto@hc.msu.edu 